\title{
FATIGUE LIFE ESTIMATION FOR SELECTED MATERIALS IN MULTIAXIAL STRESS STATES WITH MEAN STRESS
}

\author{
Krzysztof Kluger, Tadeusz Łagoda \\ Opole University of Technology, Opole, Poland \\ e-mail:k.kluger@po.opole.pl; t.lagoda@po.opole.pl
}

\begin{abstract}
This paper proposes a model for estimating fatigue life under multiaxial stress states, based on critical plane concepts, taking into account the effect of mean shear stress. The fatigue life test results calculated on the basis of the proposed model are compared to the experimental ones related to 2017A-T4 and 6082-T6 aluminium alloy, S355J0 alloy steel under constant-amplitude bending, torsion and proportional combinations of bending and torsion; Ti-6Al-4V alloy under tension-compression, torsion and combination tension-compression - torsion. For the results obtained, statistical analysis is performed by comparing the calculation results proposed by Findley and Dang Van criteria with the experimental data.
\end{abstract}

Keywords: multiaxial fatigue, mean stress, stress model

\section{Nomenclature}

$A_{\sigma}, A_{\tau} \quad-\quad$ regression constant of the fatigue curve for bending/tension-compression and for torsion, respectively

$k_{\sigma}, k_{\tau 1}, k_{\tau 2} \quad-$ normal, shear and compound (shear and normal) mean stress reduction coefficient

$m_{\sigma}, m_{\tau} \quad-$ slope coefficient of the fatigue curve for bending/tension-compression and for torsion

$N_{c a l}, N_{\exp } \quad-$ calculation and experimental fatigue life

$\alpha \quad-$ crtical plane orientation angle

$\sigma, \tau \quad-$ applied normal and shear stress

$\sigma_{f}^{\prime} \quad-$ fatigue strength coefficient

$\sigma_{a, f}, \tau_{a, f} \quad-$ fatigue limit for bending/tension-compression and for torsion

\section{Subscripts}

$a$ - amplitude, $e q$ - equivalent, $m$ - mean, $\eta$ - normal to critical plane, $\eta, a$ - amplitude in normal critical plane, $\eta, m$ - mean value in normal critical plane, $\eta s$ - shear plane, $\eta s, a$ - amplitude in shear critical plane, $\eta s, m-$ mean value in shear critical plane.

\section{Introduction}

As design and structural requirements have grown, the industry demands from researchers faster and more accurate methods for estimation of fatigue life in multiaxial load condition so as to face the challenges related to computer-aided design due to complex geometry and load history. It is necessary to reduce the multiaxial condition to an equivalent uniaxial stress state. Such reduction is made possible by so-called fatigue criteria (Carpinteri et al., 2011, 2013; Kluger and Łagoda, 2013; Macha, 1898; Karolczuk and Macha, 2008; Papuga, 2011; Kenmeugne et al., 
2012). Although there are several approaches to life estimation of metallic materials reported in the literature (Findley, 1959; Matake, 1977; Fatemi and Socie, 1998; McDiarmid, 1994), those associated with the concept of critical plane have gained widespread usage. The main difference between them relies upon the fatigue damage measure which is considered to determinate the critical plane. Fatigue life depends on a combination of stresses acting in that plane. Depending on the stress condition, environment, component geometry and stress amplitude, the fatigue process is dominated by cracking in either the maximum shear or normal stress plane. However, in such criteria, only the effect of the mean normal stress is assumed, and the effect of shear stress is not or insufficiently taken into account.

In the recent years, alternative approaches to classical models based on the critical plane have been proposed. Morel (2000) presented a critical plane model associated with the accumulated plastic strain at the grain level (in the mesoscopic scale). Papadopoulos and Panoskaltsis (1996), Papadopoulos et al. (1997) and Papadopoulos (2001) proposed a fatigue criterion where fatigue strength is determined by a linear combination of the maximum hydrostatic stress $\sigma_{H, \max }$ and amplitude of generalised shear stress $\left\langle T_{a}\right\rangle$ defined in the critical plane. In the Dang Van criterion (Dang Van, 1983; Kluger and Łagoda, 2004), the mesoscopic scale of stress observation is applied. However, the above criteria do not take into account mean shear stress either. Additional approaches were proposed by Carpinteri et al. (2014), Araujo et al. (2014).

The non-zero mean value of stress is often a result of the effect of deadweight of the working element or the entire structure, and is also a result of initial tension of load-bearing elements (such as V-belts in transmissions). The mean stress includes also residual stress resulting from material connections. In the literature on high-cycle fatigue, the effect of the mean shear stress is not examined (Findley, 1959; Matake, 1977; McDiarmid, 1994). Classic Sines approach (Sines, 1959 ) is often quoted to support that opinion. Sines (1959) concluded that application of the mean torsion stress does not affect fatigue strength of metals subjected to cyclic torsion. Such an assumption was based on the data collected by Smith $(1939,1942)$, who gathered independent test results on the fatigue limit in torsion of various metals, including steels, aluminium alloys and bronze. In the papers (Krgo et al., 2000; Kallmyer et al., 2001) on experimental tests related to the Ti-6Al-4V titanium alloy, it was proven that the mean torsion stress leads to a reduced fatigue life in comparison to symmetric loads. During the experimental tests of 2017(A)-T4 aluminium alloy (Kluger and Łagoda, 2013, 2014; Kluger, 2015) the effect of mean torsion stress on fatigue life was discovered. It must be noted that not all materials exhibit sensitivityto the mean torsion stress (e.g. 30NCD16 steel) (Niesłony et al., 2014).

This paper aims at presenting a stress-based model for estimation of fatigue life at compound stress state taking into account the mean stress (for bending and torsion). Usefulness of the model was verifiedby comparing calculation fatigue life and experimental test results of 2017A-T4 and 6082-T6 aluminium alloys (Kluger and Łagoda, 2014; Niesłony et al., 2014), S355J0 alloy steel (Pawliczek, 2000) and Ti-6Al-4V titanium alloy (Krgo et al., 2000; Kallmyer et al., 2001) for which sensitivity to mean torsion stress was discovered. The proposed model is very satisfactory in terms of calculation time. Another beneficial feature is that the material parameters used can be easily determined based on a set of experimental data of fatigue tests related topure bending and torsion and static tests.

\section{Fatigue tests}

Experimental tests have been performed on 2017A-T4 (Kluger and Łagoda, 2013, 2014; Kluger, 2015) and 6082-T6 aluminium alloys (Niesłony et al., 2014; Kluger, 2015), S355J0 alloy steel (Pawliczek, 2000) and Ti-6Al-4V titanium alloy (Krgo et al., 2000; Kallmyer et al., 2001). The strength and fatigue properties of tested materials are listed in Table 1. 
Table 1. Strength and fatigue properties of the tested materials

\begin{tabular}{|l|c|c|c|c|c|c|c|c|c|c|}
\hline $\begin{array}{c}\text { Material } \\
(\mathrm{EN})\end{array}$ & $\begin{array}{c}E \\
{[\mathrm{GPa}]}\end{array}$ & $\begin{array}{c}\sigma_{U T S} \\
{[\mathrm{MPa}]}\end{array}$ & $\begin{array}{c}R_{p 0.2} \\
{[\mathrm{MPa}]}\end{array}$ & $\begin{array}{c}\sigma_{f}^{\prime} \\
{[\mathrm{MPa}]}\end{array}$ & $\begin{array}{c}\sigma_{a f} \\
{[\mathrm{MPa}]}\end{array}$ & $\begin{array}{c}\tau_{a f} \\
{[\mathrm{MPa}]}\end{array}$ & $A_{\sigma}$ & $m_{\sigma}$ & $A_{\tau}$ & $m_{\tau}$ \\
\hline \hline $2017(\mathrm{~A})-\mathrm{T} 4$ & 72 & 545 & 395 & 987 & $142^{1)}$ & $78^{1)}$ & 21.8 & 6.9 & 20.3 & 7.1 \\
\hline $6082-\mathrm{T} 6$ & 72 & 385 & 365 & 651 & $126^{1)}$ & $74^{1)}$ & 23.8 & 8.0 & 21.4 & 7.7 \\
\hline S355J0 & 213 & 611 & 357 & 880 & 271 & 175 & 23.8 & 7.1 & 32.8 & 11.7 \\
\hline Ti-6Al-4V & 116 & 850 & 704 & 2479 & $450^{2)}$ & $260^{2)}$ & 19.6 & 5.5 & 15.3 & 4.1 \\
\hline
\end{tabular}

For aluminium alloys 2017(A)-T4, 6082-T6 and S355J0 steel, the results of tests under pure bending, torsion and two combinations of proportional constant-amplitude bending and torsion are analysed, whereas for Ti-6Al-4V titanium alloy under tension-compression, torsion and combination tension-compression - torsion. The tests for 2017(A)-T4, 6082-T6 aluminium alloys and S355J0 steel have been performed with a fatigue testing machine enabling control of bending and torque moment. The tests for Ti-6Al-4V titanium have been performed with a fatigue testing machine enabling control of strain. Stress amplitudes and their mean values are calculated as nominal stresses (without plastic strains).

\section{Comparison of the multiaxial fatigue models}

\subsection{Findley, Dang Van models}

Findley (1959) proposed to calculate the equivalent shear stress amplitude $\tau_{e q, a}$ taking into account the maximum value of normal stress $\sigma_{n, \max }$ on the plane with maximum value of the equivalent shear stress $\tau_{e q, a}$. The proposed equation is as follows

$$
\tau_{e q, a}=\tau_{n s, a}+k \sigma_{n, \max }
$$

where $k$ is the material constant including the influence of the normal stress. Findley assumed that the principal stress directions under proportional loadings do not change. The parameter $k$ is determined on the basis of the fatigue limits for the alternating torsion $\tau_{a f}$ and bending $\sigma_{a f}$ from the following equation

$$
\frac{\sigma_{a f, b}}{\tau_{a f}}=\frac{2}{1+\frac{k}{\sqrt{1+k^{2}}}}
$$

In the Dang Van criterion (Dang Van, 1983), the mesoscopic scale of stress observation is applied. In this criterion it is assumed that the material fatigue does not occur when all grains reach a stable elastic shakedown state. It means that after the initial loading period the material is subjected to isotropic hardening, and the further relation between stress and strain is expected in the elastic range. The Dang Van criterion defines the condition of crack initiation and it does not allow oneto calculate the fatigue life. The condition of exceeding the stable elastic strain state is dependent on the mesoscopic shear and hydrostatic stresses. However, it is very common to use this criterion on the macroscopic level and in a such case the condition for crack initiation is as follows

$$
\tau_{n s}(t)+k \sigma_{h}(t) \leqslant b
$$

where $\sigma_{h}$ is hydrostatic stress; $k, b$ are constants determined from uniaxial fatigue tests:

$$
k=3 \frac{\tau_{a f}}{\sigma_{a f, b}}-\frac{3}{2} \quad b=\tau_{a f}
$$

It is assumed that the critical plane is a plane with the maximum value of shear stress. 


\subsection{New proposed model}

The new fatigue life estimation model is based on the criterion by Macha (1989). The equivalent stress is a linear combination of normal and shear stresses and takes up the form

$$
\sigma_{a, e q}=B\left(\tau_{\eta s, a}+\tau_{\eta s, m}\right)+K\left(\sigma_{\eta, a}+\sigma_{\eta, m}\right)
$$

where

$$
\begin{aligned}
\sigma_{\eta, a} & =\sigma_{a} \cos \alpha^{2}+\tau_{a} \sin 2 \alpha & \sigma_{\eta, m} & =k_{\sigma} \sigma_{m} \cos \alpha^{2}+k_{\tau 1} k_{\tau 2} \tau_{m} \sin 2 \alpha \\
\tau_{\eta s, a} & =-\frac{1}{2} \sigma_{a} \sin 2 \alpha+\tau_{a} \cos 2 \alpha & \tau_{\eta s, m} & =-\frac{1}{2} k_{\sigma} \sigma_{m} \sin 2 \alpha+k_{\tau 1} k_{\tau 2} \tau_{m} \cos 2 \alpha
\end{aligned}
$$

and

$$
\begin{array}{ll}
k_{\sigma}=\sqrt{\frac{\sigma_{\max }}{\sigma_{f}^{\prime}}} & \sigma_{\max }=\sigma_{a}+\sigma_{m} \\
k_{\tau 1}=\frac{\tau_{a}}{\sqrt{3} \tau_{m}+\tau_{a}} & k_{\tau 2}=1+\frac{\sqrt{2} \sigma_{m}}{\sigma_{m}+\tau_{m}}
\end{array}
$$

The share of individual components of stress in the fatigue process depends on $B$ and $K$ coefficients. By analysing the stress condition for pure torsion and pure bending at constant-amplitude load conditions, a relationship is formulated which describes important factors for the combination of individual components. The coefficients can be presented as follows (Kluger, 2015; Łagoda and Ogonowski, 2005)

$$
B=\frac{\sigma_{a}\left(N_{f}\right)}{\tau_{a}\left(N_{f}\right)} \quad K=2-\frac{\sigma_{a}\left(N_{f}\right)}{\tau_{a}\left(N_{f}\right)}
$$

In general, the values of $B$ and $K$ coefficients are dependent on the amplitude of normal stress $\sigma_{a}$ and the amplitude of shear stress $\tau_{a}$ for a specified number of loading cycles. The values $\sigma_{a}\left(N_{f}\right)$ and $\tau_{a}\left(N_{f}\right)$ are calculated from $\mathrm{S}-\mathrm{N}$ fatigue curves for simple load states, respectively: tension (bending), shear (torsion). If there are no clear divergences between S-N curves $\left(\sigma_{a}-N_{f}, \tau_{a}-N_{f}\right)$, in order to simplify the calculations, it may be assumed $K\left(N_{f}\right)=$ const and $B\left(N_{f}\right)=$ const, e.g. for $10^{5}$ or $10^{6}$ cycles or mainly for the fatigue limit level. However, attention must be paid to make sure that the curves are parallel over the entire high-cycle range. For aluminium alloys, a change of curve inclination coefficients is quite frequent and the effect of such a phenomenon on calculation results must be analysed (Karolczuk and Kluger, 2014).

The plane with maximum shear stress $\tau_{\eta s}$ is assumed as the critical plane for the materials being examined. Analysis criterion (3.5) for zero and non-zero mean stress carried out in (Kluger and Eagoda, 2013; Kluger, 2015; Łagoda and Ogonowski, 2005) has shown that for elastic-plastic materials, the shear plane has to taken into account, whereas the normal plane for brittle materials.

The normal mean stress reduction coefficient $k_{\sigma}$ reported in Eq. $(3.7)_{1}$ depends on the applied amplitude of normal stress $\sigma_{a}$, its mean value $\sigma_{m}$ and the material constant $\sigma_{f}^{\prime}$. Along with an increase in the mean stress, the values of $k_{\sigma}$ grow proportionally.

The value of the shear mean stress reduction coefficient $k_{\tau 1}$ (see Eq. $(3.7)_{3}$ ) depends on both the applied amplitudeof shear stress $\tau_{a}$ and its mean value $\tau_{m}$. The coefficient value is highest at lower values of the mean shear stress. With such a notation of the $k_{\tau 1}$ coefficient, the effect of higher mean stress values, if they occur, is not amplified.

The compound (shear and normal) mean stress reduction coefficient $k_{\tau 2}$ reported in Eq. $(3.7)_{4}$ depends on both the applied in the specimenmean value of normal and shear stresses. If the mean stress from bending not occurs, the coefficient takes the value 1, i.e. it remains neutral 
and does not affect the equivalent stress (Eq. (3.5)). In the case of low values of the mean shear stress, the coefficient increases.

The coefficients $k_{\sigma}, k_{\tau 1}$ and $k_{\tau 2}$ are relationships developed on the basis of observations related to fatigue tests on 2017A-T4, 6082-T6, S355J0 and Ti-6Al-4V.

The number of loading cycles to failure is calculated from the following relationship

$$
N_{f}=10^{A_{\sigma}-m_{\sigma} \log \sigma_{e q, a}}
$$

derived from the high-cycle fatigue curve S-N (Basquin) equation

$$
\log N_{f}=A_{\sigma}-m_{\sigma} \log \sigma_{a}
$$

assuming $\sigma_{a}=\sigma_{e q, a}$.

\section{Models verification}

A statistical analysis is performed to assess the proposed model. The analysis involves the determination of the mean scatter $E_{m}$ described through the following relationship (Karolczuk and Macha, 2008)

$$
E_{m}=\frac{1}{n} \sum_{i=1}^{n} E^{(i)}
$$

where

$$
E^{(i)}=\log \frac{N_{c a l}^{(i)}}{N_{e x p}^{(i)}}
$$

and the scatter coefficient is given by

$$
E_{\text {std }}=\sqrt{\frac{1}{n} \sum_{i=1}^{n}\left(E^{(i)}-E_{m}\right)^{2}}
$$

where $n$ denotes the number of specimens.

The entire scatter band is expressed with the relationship

$$
E_{e q}=10 \sqrt{E_{m}^{2}+E_{s t d}^{2}}
$$

Figsures 1-12 show comparisons of the calculation fatigue life using the proposed model with the Findley and Dang Van criteria against the experimental data for uniaxial and multiaxial loadings with zero and non-zero mean stresses. The values of both mean scatter and total scatter band are also reported. For material fatigue, the minimum confidence level 95\% (Sutherland and Veers, 2000) is generally adopted, i.e. $95 \%$ of the results fall within the range of the scatter band with the coefficient equal to $E_{e q}$. Ideal consistency of the results is marked with the continuous line, and the dashed lines represent the result scatter in the band with 2 and 3 coefficient (see Figs. 1-12).

Figures 1-3 show the comparison between the calculated and experimental fatigue life for 2017A-T4 aluminium alloy. For loadings with the zero mean stress, all of analyzed models give satisfactory results of the calculated fatigue life (close to 3). In the case of loadings with a non-zero mean stress, the calculations based on the proposed model give the smallest scatter $\left(E_{e q}=2.99\right)$. Other models of calculations give a very larges cattering of the results. Findley and Dang Van models overestimate fatigue life calculation. 

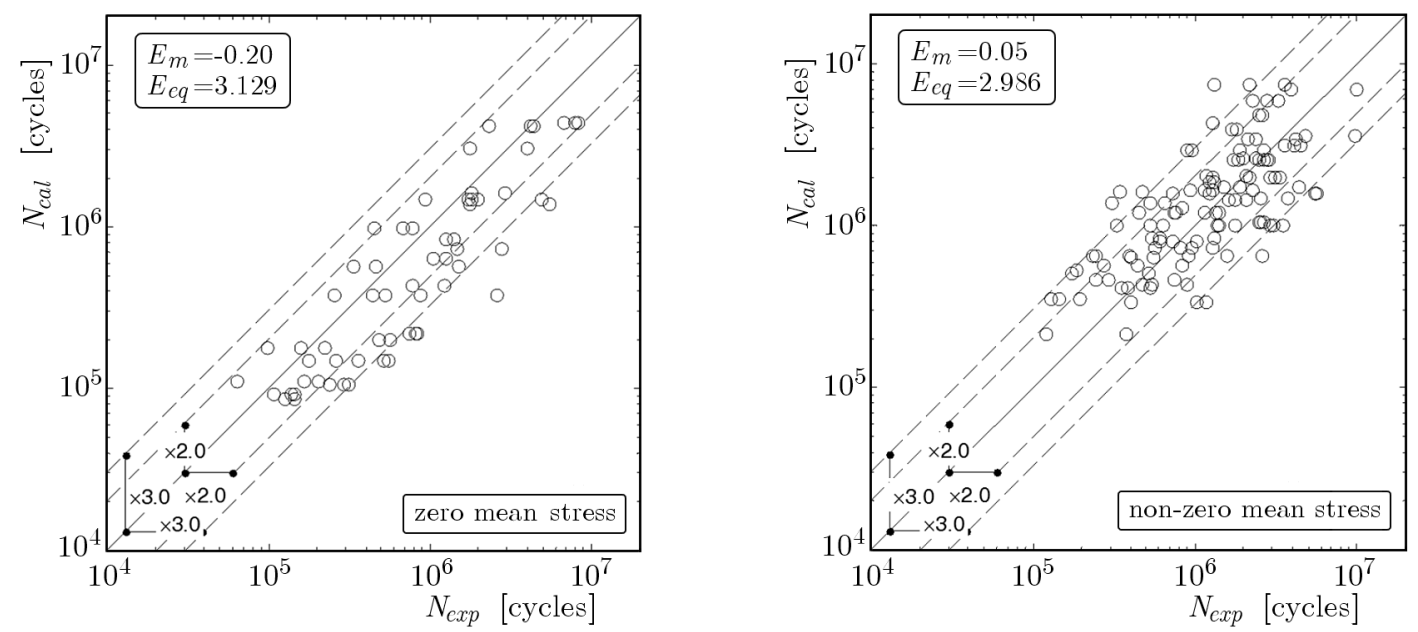

Fig. 1. Comparison of the calculated and experimental fatigue lives for aluminum alloy 2017A-T4 using the proposed model
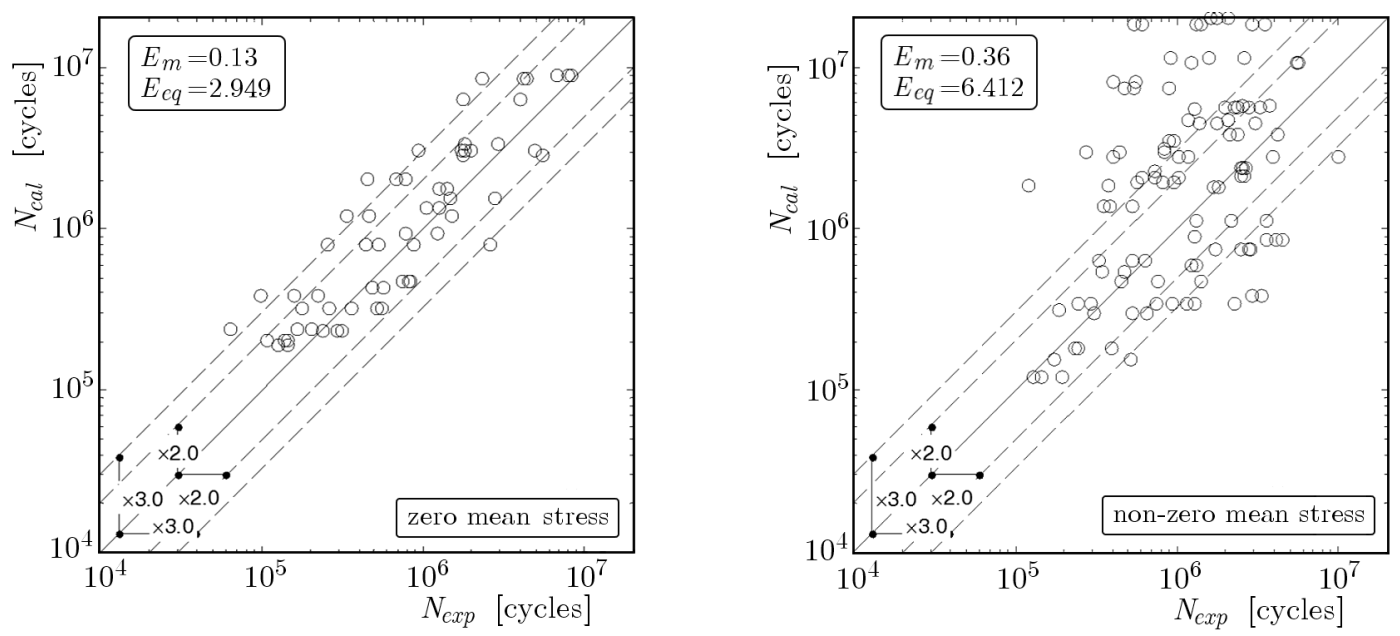

Fig. 2. Comparison of the calculated and experimental fatigue lives for aluminum alloy 2017A-T4 using Findley criterion
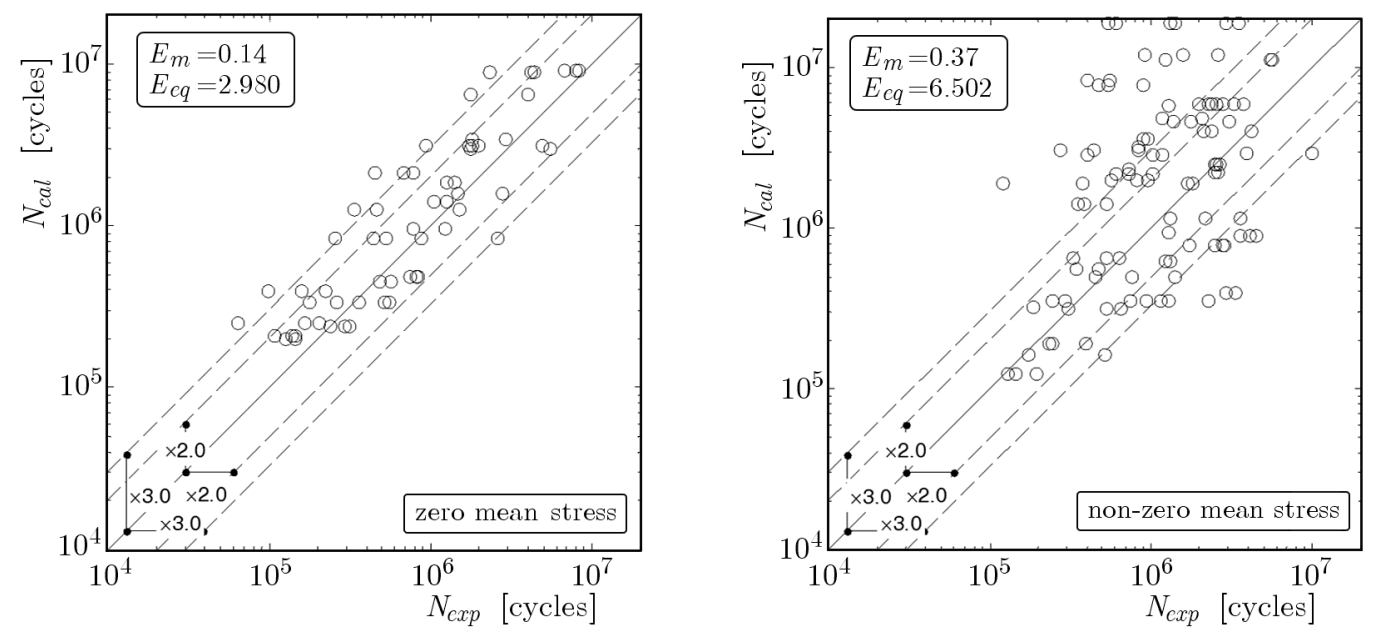

Fig. 3. Comparison of the calculated and experimental fatigue lives for aluminum alloy 2017A-T4 using Dang Van criterion 

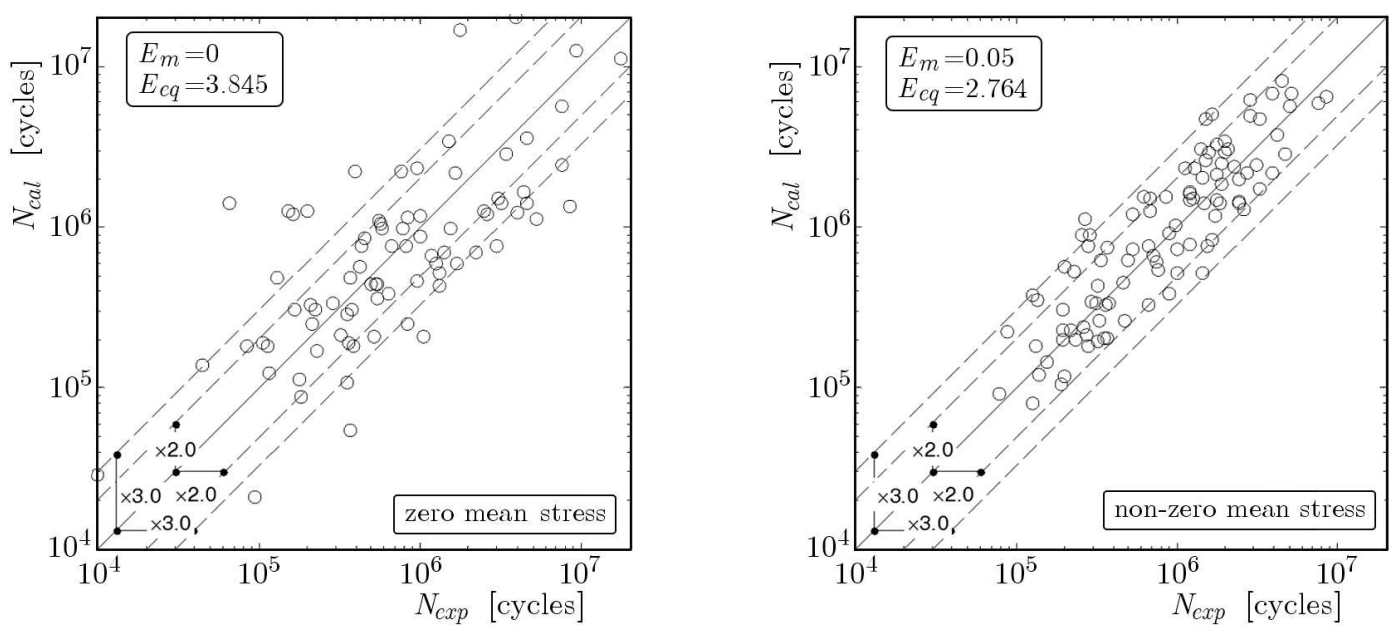

Fig. 4. Comparison of the calculated and experimental fatigue lives for aluminum alloy 6082-T6 using the proposed model
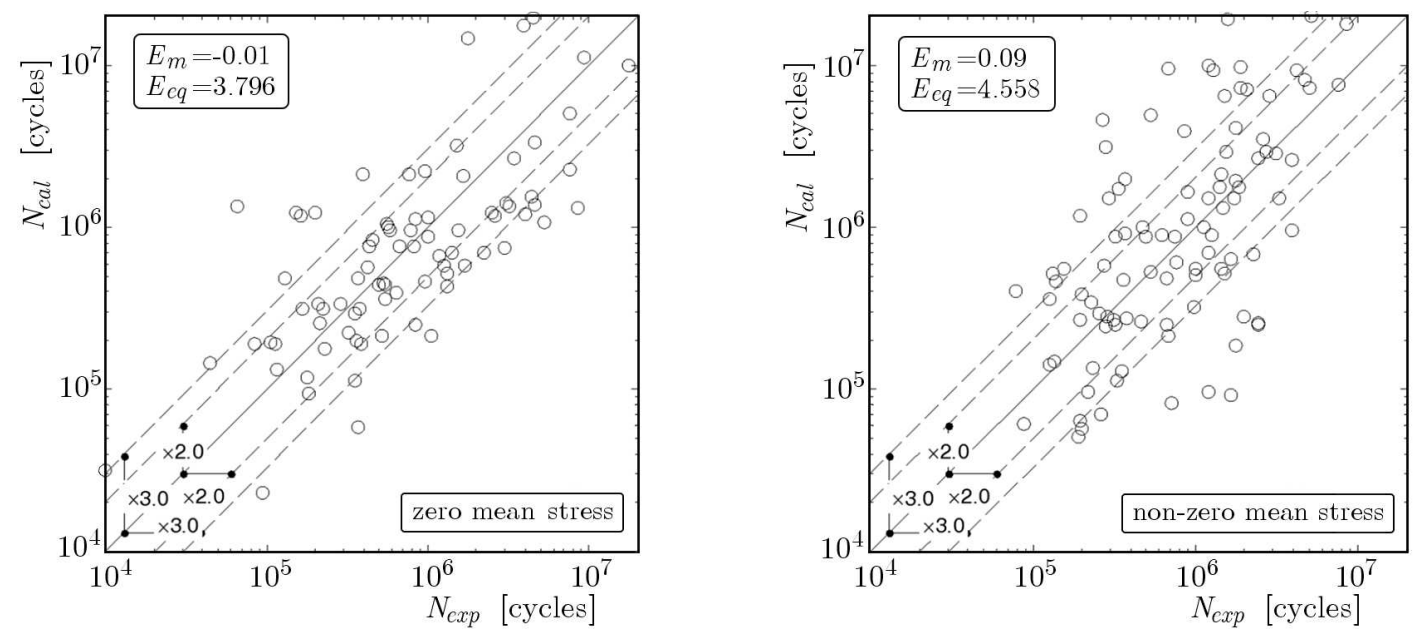

Fig. 5. Comparison of the calculated and experimental fatigue lives for aluminum alloy 6082-T6 using Findley criterion
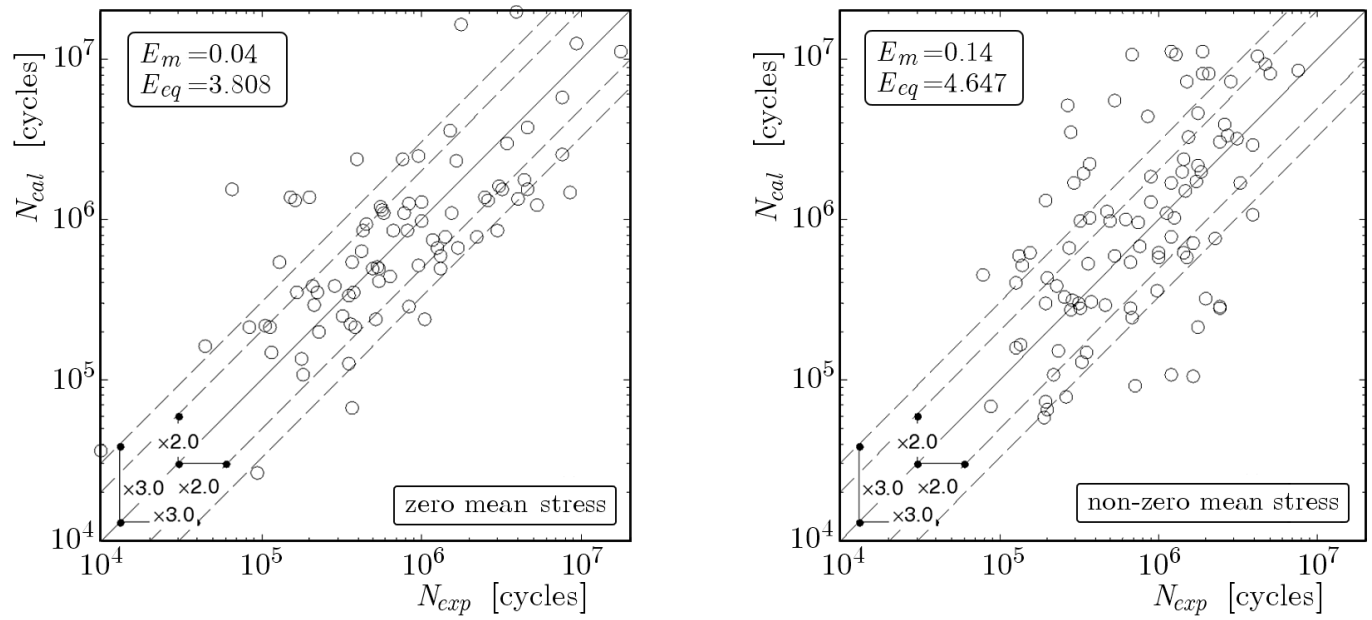

Fig. 6. Comparison of the calculated and experimental fatigue lives for aluminum alloy 6082-T6 using Dang Van criterion 

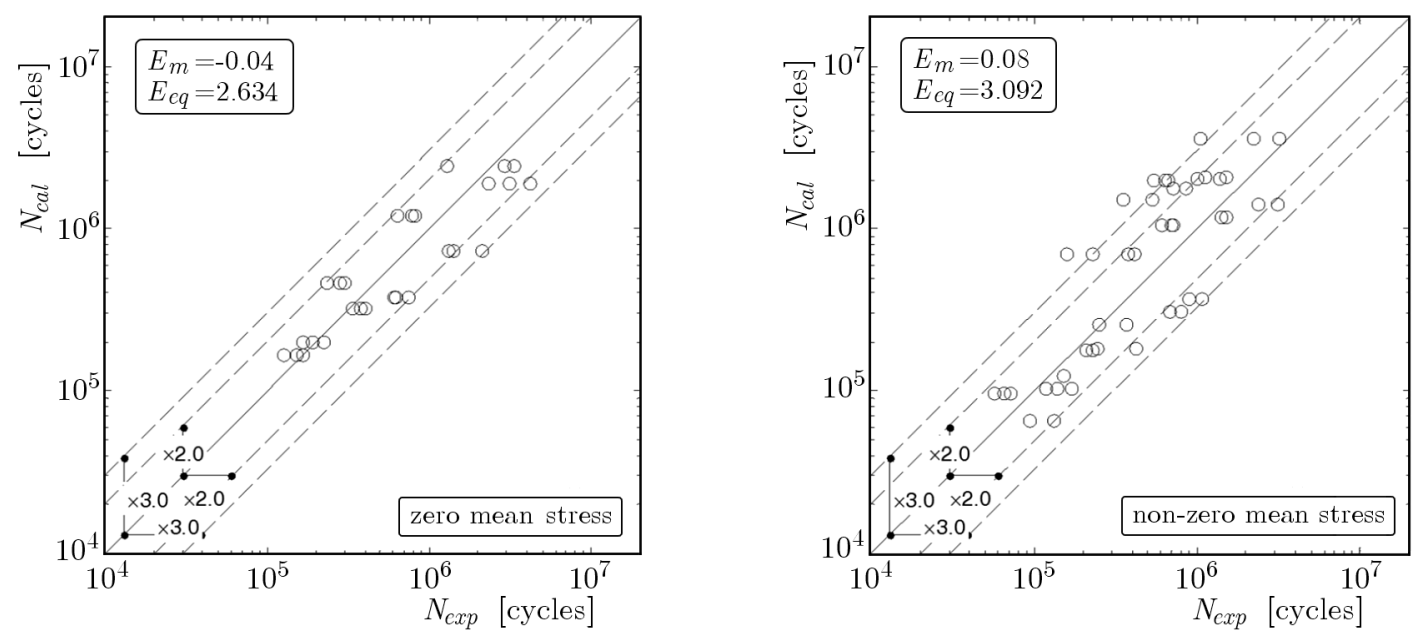

Fig. 7. Comparison of the calculated and experimental fatigue lives for steel alloy S355J0 using the proposed model
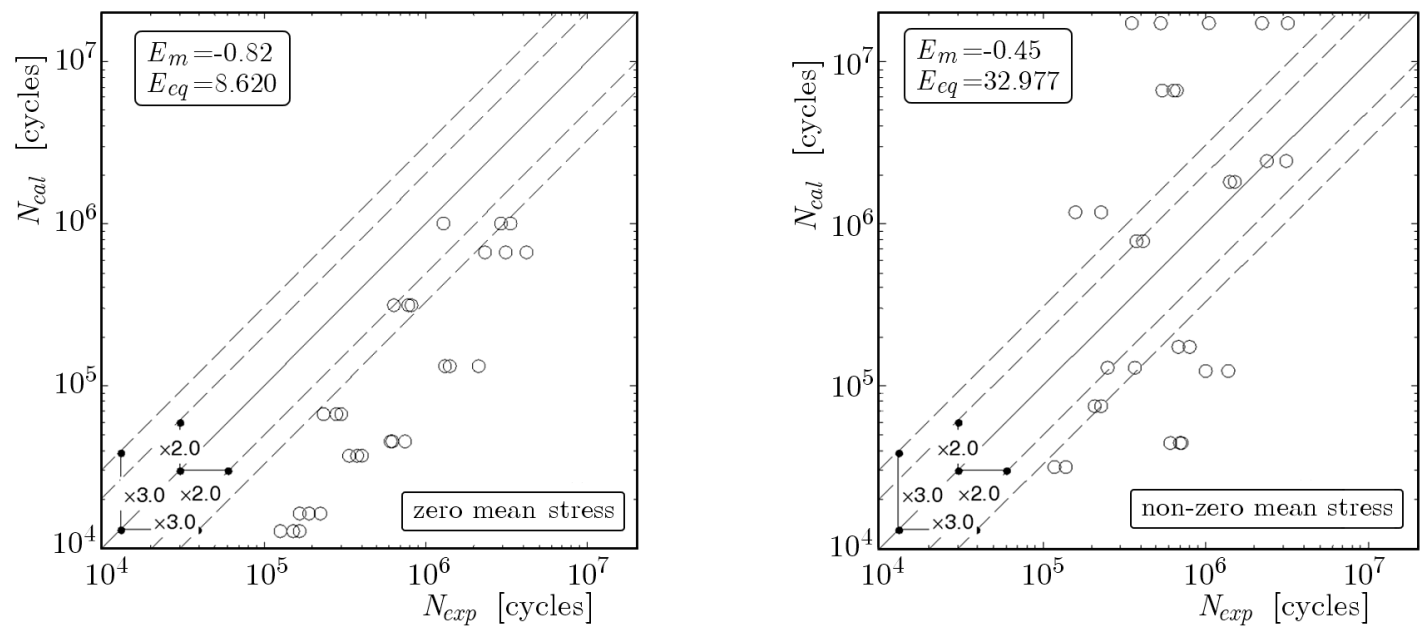

Fig. 8. Comparison of the calculated and experimental fatigue lives for steel alloy S355J0 using Findley criterion
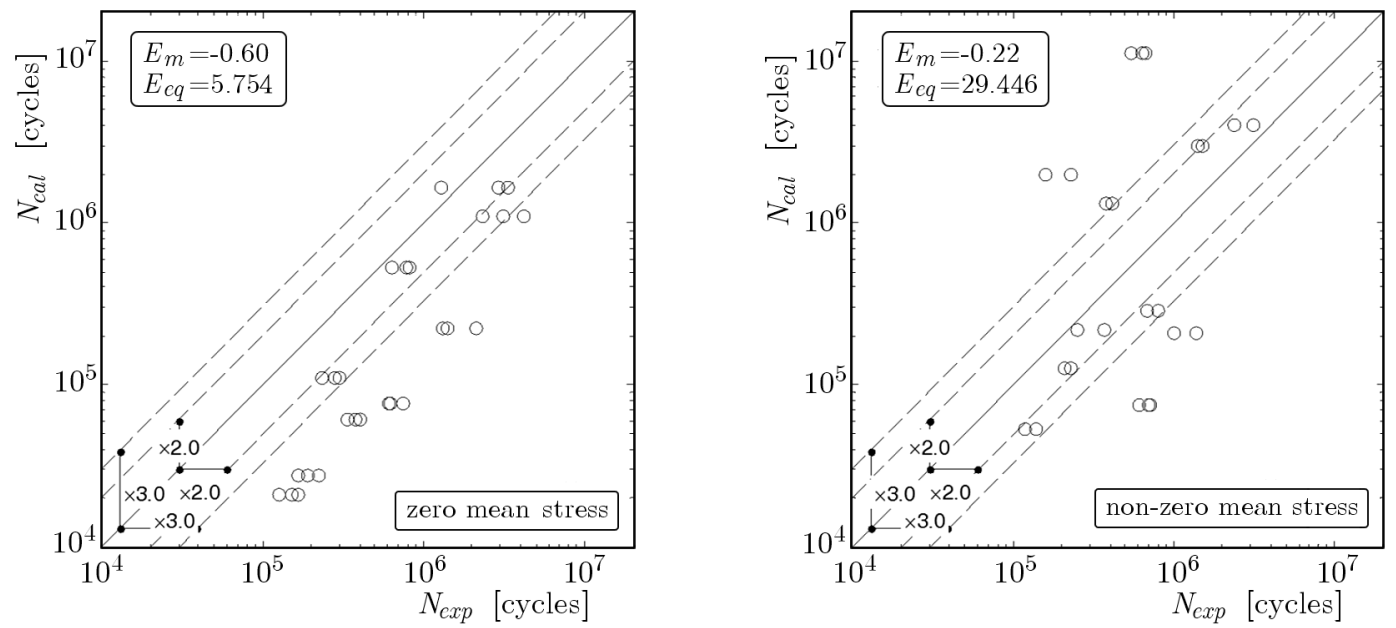

Fig. 9. Comparison of the calculated and experimental fatigue lives for steel alloy S355J0 using Dang Van criterion 

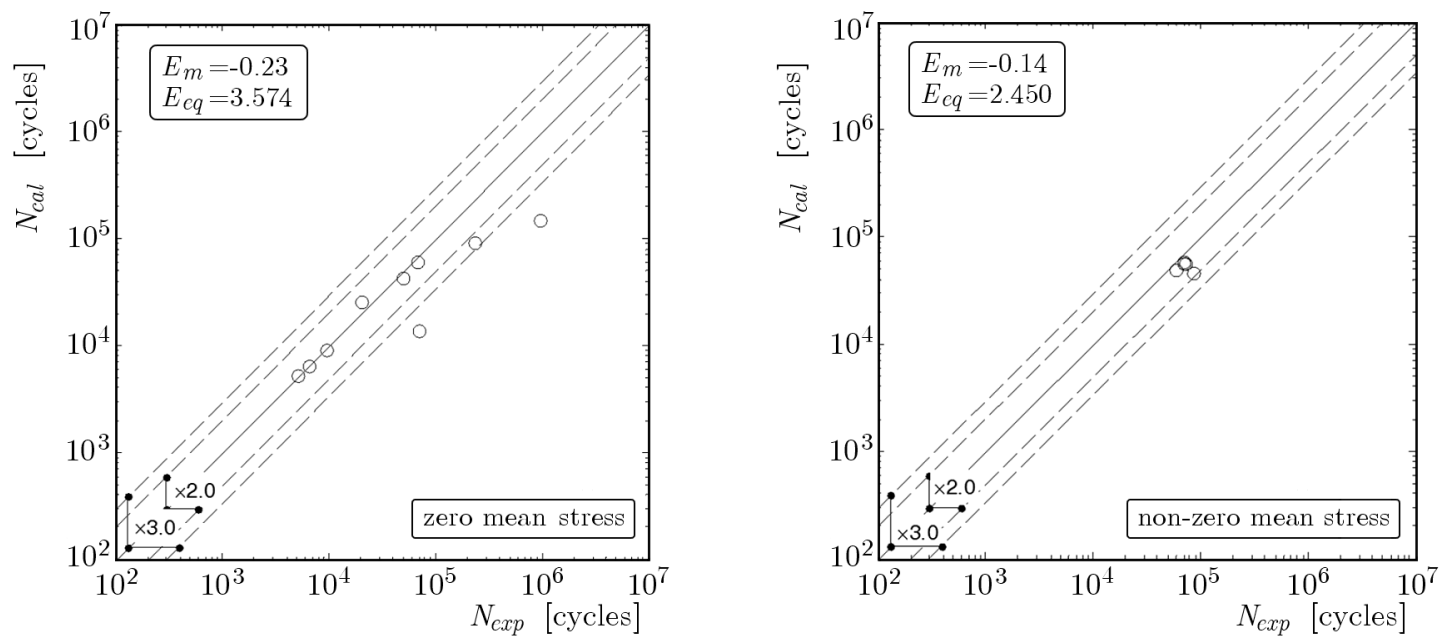

Fig. 10. Comparison of the calculated and experimental fatigue lives for titanium alloy Ti-6Al-4V using the proposed model
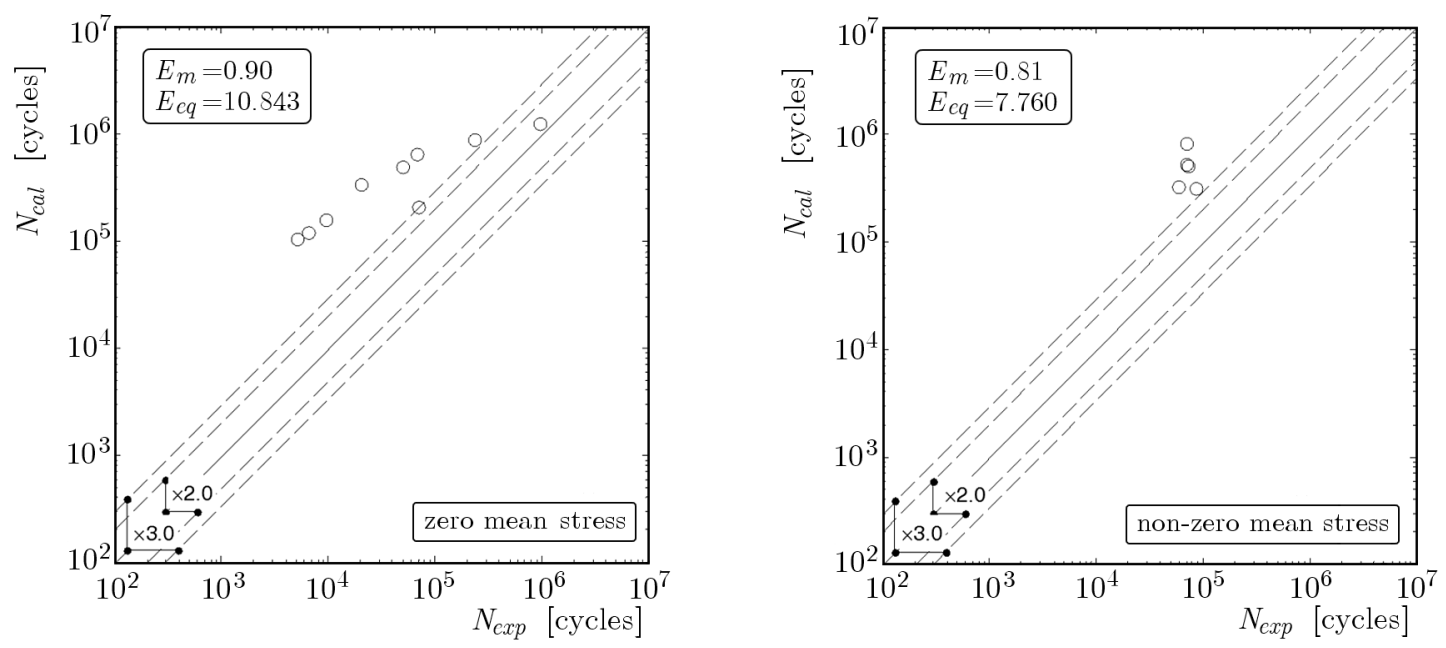

Fig. 11. Comparison of the calculated and experimental fatigue lives for titanium alloy Ti-6Al-4V (Findley criterion)
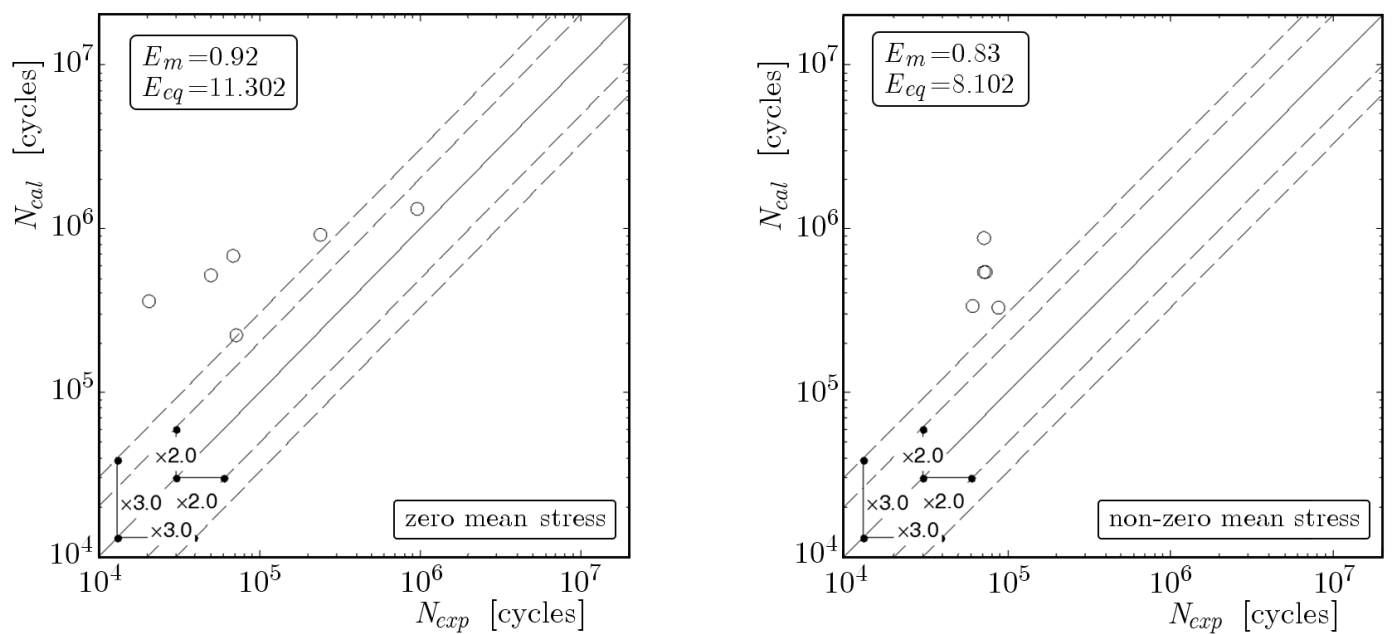

Fig. 12. Comparison of the calculated and experimental fatigue lives for titanium alloy Ti-6Al-4V (Dang Van criterion) 
For 6082-T6 aluminium alloy, for which the results of the comparison are shown in Figs. 4-6, the smallest scattering for the zero mean loading are obtained using Findley's model $\left(E_{e q}=3.71\right)$, but the other models gives similar results. The large scatter of the data is a result of the very large scatter in the experimental results. The proposed model applied for fatigue life calculation with a non-zero mean stress provides satisfactory results of the calculated fatigue life for which the scatter band is less than 3. Other models of calculations give a very large scattering of the results.

The comparison between the calculated and experimental fatigue life with the zero mean stress for two other analyzed materials S355J0 (see Figs. 7-9) and Ti-6Al-4V (see Figs. 10-12) show that the Findley and Dang Van models overestimate fatigue life calculation. Similar results are obtained for non-zero mean stresses. Only the proposed model applied for fatigue life calculation with the zero mean stress provides satisfactory results of the calculated fatigue life for zero and non-zero mean stresses.

The model presented is suitable for estimation of fatigue life of materials dependent on the mean torsion stress (2017A-T4, 6082-T6, S355J0, Ti-6Al-4V) as is proven by a statistical analysis. The share of the mean bending and torsion stress in the model is limited by the reduction coefficients $k_{\sigma}, k_{\tau 1}$ and $k_{\tau 2}$. The coefficients applied allow one to estimate fatigue life also for the combination of bending and torsion. For non-proportional loads with zero mean stresses, criterion (3.5) gives good results of the estimated fatigue life (Walat et al., 2012). Due to the lack of other studies and limited number of experimental data, the suitability of the model to estimate the fatigue life of non-proportional loads with a non-zero mean value cannot be definitively determined. Only for one of the materials (steel 30NCD16), experimental studies for non-proportional loads of a non-zero mean value of stress (Froustey and Lasserre, 1989) were carried out. Unfortunately, this material is not sensitive to the mean shear stress.

The model proposed is very satisfactory in terms of calculation time. Another beneficial feature of the model is that the material parameters used can easily be determined based on a set of experimental data of fatigue tests related to pure bending and torsion and static tests. The coefficients $k_{\tau 1}$ and $k_{\tau 2}$ depend on the load state only.

The results of experimental tests outside the scatter band with the coefficient equal to 3 can be due to the fact that the material for tests is of commercial quality, without homogenisation and normalisation after mechanical treatment.

\section{Conclusions}

- As a result of verifications of the presented model, satisfactory results of comparisons between the calculation and experimental data have been obtained for 2017A-T4 and 6082-T6 aluminium alloys, S355J0 steel alloy and Ti-6Al-4V titanium alloy for all types of load analyzed.

- Mean torsion stresses affect fatigue life of the materials analysed, and have to be taken into account in the calculation process.

- The value of the shear mean stress reduction coefficient $k_{\tau 1}$ depends on both the amplitude of shear stress and its mean value. The coefficient is highest at lower values of the mean shear stress.

- The compound (shear and normal) mean stress reduction coefficient $k_{\tau 2}$ depends on values of both mean normal and shear stresses. If the mean stress from bending does not occur, the coefficient takes the value 1, i.e. it does not affect the equivalent stresses. In the case of low values of mean shear stress, the coefficient increases. 
- The material susceptibility to the mean stress coefficient $k_{\sigma}$ depends on the amplitude of the normal stress $k_{\sigma}$ and the fatigue life coefficient $\sigma_{f}^{\prime}$. Along with an increase in the mean stress, the values grow proportionally.

- The reason for large scatter of the results for the other analyzed models could be the disregarding of the effect of the mean shear stress.

\section{References}

1. Araujo J.A., Carpinteri A., Ronchei C., 2014, An alternative definition of the shear stress amplitude based on the Maximum Rectangular Hull method and application to the C-S (Carpinteri-Spagnoli) criterion, Fatigue and Fracture of Engineering Materials and Structures, 37, 7, 764-771

2. Carpinteri A., Spagnoli A., Vantadori S., 2011, Multiaxial assessment using a simplified critical plane-based criterion, International Journal of Fatigue, 33, 969-976

3. Carpinteri A., Spagnoli A., Vantadori S., 2014, Reformulation in the frequency domain of a critical plane-based multiaxial fatigue criterion, International Journal of Fatigue, 67, 55-61

4. Carpinteri A., Spagnoli A., Vantadori S., Bagni C., 2013, Structural integrity assessment of metallic components under multiaxial fatigue: the C-S criterion and its evolution, Fatigue and Fracture of Engineering Materials and Structures, 36, 870-883

5. DANG VAN K., 1983, Macro-micro approach in high-cycle multiaxial fatigue, American Society for Testing and Materials, STP 1191, 120-130

6. Fatemi A., Socie D.F., 1998, A critical plane approach to multiaxial fatigue damage including out-of-phase loading, Fatigue and Fracture of Engineering Materials and Structures, 11, 3, 149-165

7. Findley W.N., 1959, A theory for the effect of mean stress on fatigue of metals under combined torsion and axial load or bending, Journal of Engineering for Industry, 301-306

8. Froustey C., Lasserre S., 1989, Multiaxial fatigue endurance of 30NCD16 steel, International Journal of Fatigue, 11, 3, 169-175

9. Kallmeyer A.R., Krgo A., Kurath P., 2001, Multiaxial fatigue life prediction methods for notched bars of Ti-6Al-4V, Proceedings of the 6th National Turbine Engine High Cycle Fatigue Conference, Jacksonville

10. Karolczuk A., Kluger K., 2014, Analysis of the coefficient of normal stress effect in chosen multiaxial fatigue criteria, Theoretical and Applied Fracture Mechanics, 73, 39-47, doi: 10.1016/j.tafmec.2014.07.015

11. Karolczuk A., Macha E., 2008, Selection of the critical plane orientation in two-parameter multiaxial fatigue failure criterion under combined bending and torsion, Engineering Fracture Mechanics, 75, 389-403

12. Kenmeugne B., Soh Fotsing B.D., Anago G.F., Fogue M., Robert J.-L., Kenne J.-P., 2012, On the evolution and comparison of multiaxial fatigue criteria, International Journal of Engineering and Technology, 4, 1, 37-46

13. Kluger K., 2015, Fatigue life estimation for 2017A-T4 and 6082-T6 aluminium alloys subjected to bending-torsion with mean stress, International Journal of Fatigue, 80, 22-29, doi: 10.1016/j.jfatigue.2015.05.005

14. Kluger K., Łagoda T., 2004, Application of the Dang-Van criterion for life determination under uniaxial random tension-compression with different mean values, Fatigue and Fracture of Engineering Materials and Structures, 27, 505-512

15. Kluger K., Łagoda T., 2013, Fatigue life of metallic material estimated according to selected models and load conditions, Journal of Theoretical and Applied Mechanics, 51, 3, 581-592

16. Kluger K., EAgoda T., 2014, New energy model for fatigue life determination under multiaxial loading with different mean values, International Journal of Fatigue, 66, 229-245 
17. Krgo A., Kallmeyer A.R., Kurath P., 2000, Evaluation of HCF multiaxial fatigue life prediction methodologies for Ti-6Al-4V, Proceedings of the 5th National Turbine Engine High Cycle Fatigue Conference, Arizona

18. Łagoda T., Ogonowski P., 2005, Criteria of multiaxial random fatigue based on stress, strain and energy parameters of damage in the critical plane, Mat.-wiss. u. Werkstofftech, 36, 9, 429-437

19. MACHA E., 1989, Generalization of fatigue fracture criteria for multiaxial sinusoidal loadings in the range of random loadings, [In:] Biaxial and Multiaxial Fatigue, EGF 3, M.W. Brown and K.J. Miller (Edit.), Mechanical Engineering Publications, London, 425-436

20. Matake T., 1977, An explanation on fatigue limit under combined stress, Bulletin of the JSME, 20, 257-263

21. McDiarmid D.L., 1994, A shear-stress based critical-plane criterion of multiaxial fatigue failure for design and life estimation, Fatigue and Fracture of Engineering Materials and Structures, 17, $12,1475-1484$

22. Morel F., 2000, A critical plane approach for life estimation of high cycle fatigue under multiaxial variable amplitude loading, International Journal of Fatigue, 22, 2, 101-119

23. NiesŁony A., Eagoda T., Walat K., ET Al., 2014, Multiaxial fatigue behaviour of AA6068 and AA2017A aluminium alloys under in-phase bending with torsion loading condition, Mat.-wiss. u. Werkstofftech, 45, 10, 947-952

24. Papadopoulos I.V., 2001, Long life fatigue under multiaxial loading, International Journal of Fatigue, 23, 831-849

25. Papadopoulos I.V., Davoli P., Gorla C., Filippini M., Bernasconi A., 1997, A comparative study of multiaxial high-cycle fatigue criteria for metals, International Journal of Fatigue, 19, $3,219-235$

26. Papadopoulos I.V., Panoskaltsis V.P., 1996, Invariant formulation of a gradient dependent multiaxial high-cycle fatigue criterion, Engineering Fracture Mechanics, 55, 4, 513-528

27. Papuga J., 2011, A survey on evaluating the fatigue limit under multiaxial loading, International Journal of Fatigue, 33, 153-165

28. PawliczeK R., 2000, Fatigue Fracture Plane Orientation Under Combined Bending and Torsion for 18G2A Steel, Opole University of Technology, Faculty of Mechanical Engineering, Opole, Poland

29. Sines G., 1959, Behaviour of metals under complex static and alternating stresses, [In:] Metal Fatigue, Sines G., Waisman J.L. (Edit.), New York, McGraw-Hill, 5-14

30. Sмith J.O., 1939, The effect of range of stress on the torsional fatigue strength of steels, Bulletin Series No. 316, Engineering Experiment Station, University of Illinois

31. Sмith J.O., 1942, The effect of range of stress on the torsional fatigue strength of metals, Bulletin Series No. 334, Engineering Experiment Station, University of Illinois

32. Sutherland H.J., Veers P.S., 2000, The development of confidence limits for fatigue strength data, Wind Energy, ASME/AIAA

33. Walat K., Kurek M., Ogonowski P., Eagoda T., 2012, The multiaxial random fatigue criteria based on strain and energy damage parameters on the critical plane for the low-cycle range, International Journal of Fatigue, 37, 100-111 